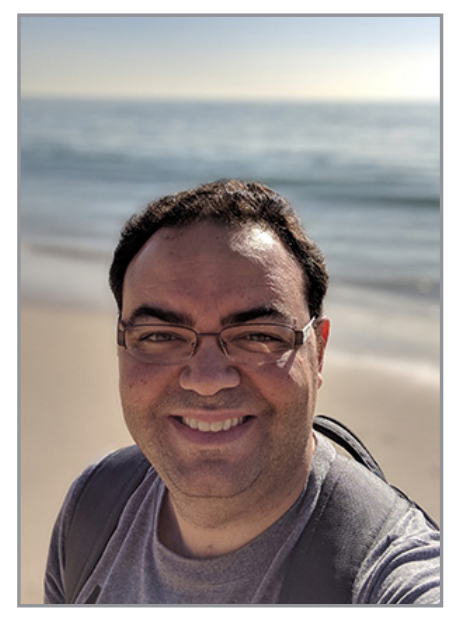

\title{
Portable Analytical Techniques for Forensic Applications
}

\author{
Thiago R. L. C. Paixão \\ Associate Professor \\ Department of Fundamental Chemistry, Institute of Chemistry \\ University of São Paulo, SP, Brazil \\ trlcp@iq.usp.br
}

Forensic chemistry is defined as the science that deals with the analysis, classification, and quantification of elements or substances during the investigation of crime scenes, so that they could be used as valid evidence during subsequent legal proceedings. A variety of professionals from the field of chemistry are involved in forensics, including organic, inorganic, physical and analytical chemists.

Analytical chemists occupy an important position in the field of forensic chemistry, because most investigations require the development or application of a technique pertaining to analytical chemistry for the examination, identification, and/or comparison of materials collected from crime scenes. In some cases, real-time analyses of the materials collected in-situ from crime scenes are suitable by using portable devices or methods.

The concept of using analytical chemistry as a method to establish evidence (or otherwise) against/ in favor of the accused was pioneered in London for the trial of John Bodle in 1832, who was accused of murdering his grandfather by arsenic poisoning. The British chemist James Marsh proposed the use of chemical techniques to detect traces of arsenic in the stomach of the corpse. Although Marsh was successful in determining the presence of arsenic, but the test results had deteriorated before they could be presented to the jury and the judge. As a result, Bodle was acquitted, although he confessed to the murder later. Looking for a more reliable test in crime investigation, Marsh proposed the Marsh test. It was an improvement over the Scheele's test that involved the reaction of arsenic powder with metallic zinc and nitric acid in the presence of heat to form arsine gas $\left(\mathrm{AsH}_{3}\right)$. Marsh confined the formed arsine gas inside a funneled tube and re-heated it. The trapped arsine gas was decomposed into a gray metallic film, forming an "arsenic mirror" that could be used as evidence in the courtroom [1]. This test was used to establish the guilt of Marie LaFarge, who was accused of using arsenic to poison her husband. Hence, the development and use of analytical techniques occupy an important position in contemporary crime investigation as tools to detect and quantify chemicals found in crime scenes. For example, most modern analytical laboratories use sophisticated methods such as atomic absorption spectrometry and inductively coupled plasma mass spectrometry to detect arsenic in a biological sample. Apart from the methods listed above, some non-standard techniques are being increasingly used in forensic analysis because of their enhanced portability and reduced costs $[2,3]$.

The portable techniques could be very helpful for in-situ forensic analysis at crime scenes. For example, if a large amount of evidence is uncovered from a crime scene, conventional analytical methods would involve the investment of a lot of time and effort in performing definitive analyses of all the substances in order to classify them and determine their nature. A batch of seized material presumed to be cocaine could end up being something that is entirely irrelevant and/or harmless, thus rendering the entire endeavor wasted. Hence, quick preliminary field analyses are extremely important to reduce the number of definitive analyses. As a result, portable techniques are applicable 
because they are widely used as an initial step to analyze suspicious materials or illicit substances. Thus, portable techniques minimize the necessity of storing a large number of samples, which is a requirement when conventional methods of analysis are applied. This field has garnered considerable research interest, and consequently the number of publications in analytical chemistry literature about the portable techniques is increasing steadily [2,3]. However, these methods need further development to be readily applicable in the field of forensic analysis.

1. Marsh, J. Edinburgh New Philos. J., 1836, 21, pp 229-236.

2. Oliveira, L. P.; Rocha, D. P.; Araujo, W. R.; Muñoz, R. A. A.; Paixão, T. R. L. C.; Salles, M. O. Anal. Methods, 2018, 10, pp 5135-5163.

3. Araujo, W. R.; Cardoso, T. M. G.; Rocha, R. G.; Santana, M. H. P.; Muñoz, R. A. A.; Richter, E. M.; Paixão, T. R. L. C.; Coltro, W. K. T. Anal. Chim. Acta, 2018, 1034, pp 1-21. 